Research Article

\title{
Antibacterial Potential of Silver Nanoparticles Synthesized using Aqueous Flower Extract of
} Lantana camera L.

\author{
Disha Dhabarde*, Nikita Gaydhane, Manish Kamble, Ashwini Ingole, Jagdish Baheti \\ Kamla Nehru College of Pharmacy, Butibori, Nagpur. (M.S.), India. \\ *Corresponding author's E-mail: dishamandave@gmail.com
}

Received: 10-01-2021; Revised: 20-02-2021; Accepted: 28-02-2021; Published on: 20-03-2021.

\section{ABSTRACT}

Though silver nanoparticles (AgNPs) biosynthesized and mediated by plant extracts, they have seen to possess several pharmacological activities. They are widely used as medicine in pharmaceutical industries. The current investigation aimed and designed to evaluate antibacterial potential of biosynthesized silver nanoparticles (AgNPs) of flower extract of Lantana camera L. The AgNPs were biosynthesized using silver nitrate $(1 \mathrm{mM})$ solution and treated with flower extract. Yellow brown color indicating the formation of AgNPs. These particles were characterized by Ultraviolet-Visible (UV-Vis) spectroscopy and Scanning Electron Microscope (SEM). An anti-bacterial study using an agar well diffusion technique was employed for the biosynthesized AgNPs on Staphylococcus aureus (S. aureus).

Keywords: Antibacterial, Silver Nanoparticles (AgNPs), Lantana camara, Spectral analysis.

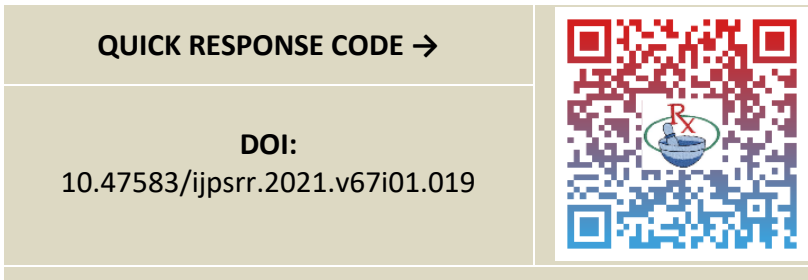

DOI link: $\underline{\text { http://dx.doi.org/10.47583/ijpsrr.2021.v67i01.019 }}$

\section{INTRODUCTION}

$\mathrm{n}$ the fast-growing field of science and biotechnology, formation of remarkable and revolutionized material known as Nanomaterial. These nanoparticles of 1$100 \mathrm{~nm}$ range has the diverse application in medicine, drug delivery, imaging \& diagnosis ${ }^{1}$. The synthesis and characterization of novel metal nanoparticles such as silver, gold, and platinum is emerging field. Such material have vital role in different activities due to their unique size that are more influenced than their own metal ions. Biosynthesis of these metallic nanoparticles characterized by high ratio of surface area to mass as compared to that bulk material ${ }^{2}$. NPs are conjugated with a variety of functionalized biomolecules and therefore having application in diagnosing, targeting, delivering and treating the drug in various ailments ${ }^{3}$. Medicinal use of silver has been documented since ancient times. In Ayurveda and Chinese medicinal system, it has been reported to have antimicrobial activities ${ }^{4}$. AgNPs are also used to treat open wound infections, chronic ulcers, ${ }^{5}$ textile industries, water purification systems, medical and diagnostic devise, household appliances and electronics, cosmetics \& medicines $^{6}$. NPs have been synthesized by several methods. Physical or chemical methods are expensive and needs reductants or radiation which is harmful to humans as well as environment. However, as compared to expenditure, less energy, eco-friendly natural method is biological synthesis from plants, microbes and enzymes. Among all biological systems, plant extract mediated synthesis is faster and NPs so synthesized are more stable ${ }^{7}$.

Lantana camara L. (Verbanaceae) is a flowering and ornamental herb found in tropical and sub-tropical countries commonly known as wild or red sage. It has wide traditional claims for treatment of various illness ${ }^{8}$. The stems and branches are sometimes thorny. Flower heads contain 20-40 flowers, usually $2.5 \mathrm{~cm}$ across; the color of flowers varies from white, cream or yellow to orange pink, purple and red with small, rounded heads, often in two colors.

\section{MATERIALS AND METHOD}

\section{Chemicals}

Sigma-Aldrich (Germany) remained the chief supplier of silver nitrate. The reagents employed in the study were of analytical grade and purchased from HiMedia (India). Double distilled water was employed during the experiment (Borosil, India) ${ }^{\circledR}$.

\section{Collection of plant material}

The flowers of Lantana camara were collected from the shrubs present in the Butibori region of Nagpur, Maharashtra, India. The plant was recognized and authenticated by Dr. Dongarwar, Department of Botany, RTM Nagpur University, Nagpur, Maharashtra.

\section{Preparation of Extract}

Fresh flowers of Lantana camara were collected and aqueous extract was prepared. $15 \mathrm{~g}$ of powdered Lantana camara was dissolved in $200 \mathrm{ml}$ of distilled water. The mixture was heated on hot plate with continuous stirring at $30-40{ }^{\circ} \mathrm{C}$ for 20 minutes. Then, the water extract was filtered through filter paper. The filtrate was kept in a 
beaker and allowed to dry by heating in a boiling water bath. The gummy residue obtained was used for quantitative and qualitative determination.

\section{Preparation of Silver Nitrate solution}

$1 \mathrm{mM}$ aqueous solution of silver nitrate $\left(\mathrm{AgNO}_{3}\right)$ was prepared and used for synthesis of nanoparticles. To prepare $100 \mathrm{ml}$ of $1 \mathrm{mM}$ solution, $0.01698 \mathrm{~g}$ of $\mathrm{AgNO}_{3}$ was added to $100 \mathrm{ml}$ of distilled water.

\section{Synthesis of Silver Nanoparticles}

The fabrication of the silver nanomaterials involved a reaction of fresh fruit flesh extract $(1 \mathrm{~mL})$ with $9 \mathrm{~mL}$ of $1 \mathrm{mM}$ aqueous solution of $\mathrm{AgNO}_{3}$ and further incubation of the content for 24 hours at $37^{\circ} \mathrm{C}$. The change in the color of the mixture was checked, since it is an indicator of nanoparticles formation.

\section{Characterization of silver nanoparticles}

\section{UV-Vis spectroscopic study}

The UV-Vis spectrophotometer (Shimadzu ${ }^{\circledR}$ UV-1800) was employed in studying the reduction of pure silver ions. For this study, the samples (pure $\mathrm{AgNO}_{3}$ solution and the prepared AgNP solution) in small aliquots with double distilled water were scanned in the wavelength range of 200-800 $\mathrm{nm}$ after 24 hours.

\section{Scanning electron microscopic study}

The scanning electron microscopy (SEM) technique (JOELJSM 6390 SEM) was employed comprehensively studying the morphology of the prepared nanomaterial. The samples were analyzed by initially sprinkling the content over the double tape hold to the aluminium stub, followed by installing in the SEM chamber and subsequently scanning at the acceleration voltage of $10 \mathrm{kV}$. The scanned photomicrographs were recorded and saved.

\section{Antibacterial activity}

The potential of the fabricated silver nanoparticles in exhibiting bactericidal activity against pathogenic Staphylococcus aureus (S. aureus, MTCC 3160) were evaluated suitably. The in-vitro antibacterial study was executed by disc diffusion method using the Muller Hinton Agar medium. Initially, the microbes were cultured in the nutrient broth and further incubated at $37 \pm 1^{\circ} \mathrm{C}$ for $24 \mathrm{hr}$. Subsequently, the cultured cells were multiplied in the Muller Hinton agar plates. The AgNPs containing discs were screened against $S$. aureus and compared with ciprofloxacin (positive control). The zone of inhibition (ZOI) was measured in millimetres $(\mathrm{mm})$. The experiment was performed in triplicate manner. The minimum inhibitory concentration (MIC) was performed by the agar streak dilution method. The MIC value was determined and the average was taken ${ }^{9}$.

\section{RESULTS AND DISCUSSION}

The study revealed that, with the addition of plant extract to the aqueous silver nitrate solution, a change in color of the content was observed after few hours. This certainly indicated the formation of AgNPs in the medium by the reduction of ionic silver to elemental silver form.

\section{UV-Vis spectroscopic study}

The reduced sample displayed an optical absorption band peak at $335 \mathrm{~nm}$, which was due to absorption attributes of metallic Ag as a result of Surface Plasmon Resonance (SPR). An increase in intensity was noticed which may be due to the formation of AgNPs in a time-dependent manner. The absorption peak at $335 \mathrm{~nm}$ reflects that abundant organic molecules interacted with the silver ions in the solution. In contrast, the absorption band at 250 to $300 \mathrm{~nm}$ specified that capping occurred after the formation of AgNPs. Figure 1 depicts the UV spectra of Lantana camara mediated synthesized AgNP sample.

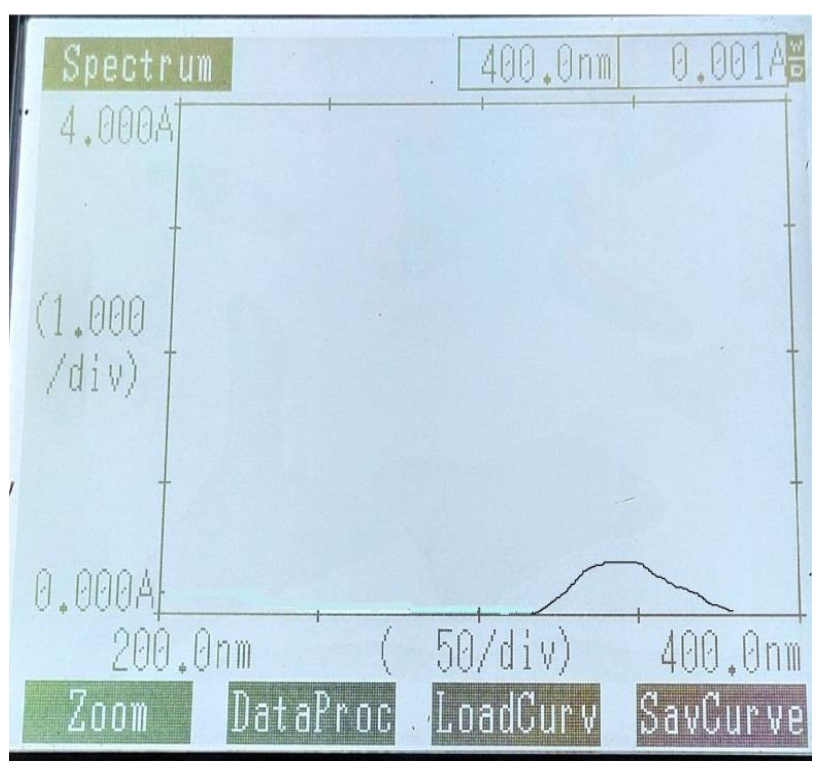

Figure 1: UV spectrum of Lantana camara mediated synthesized AgNP sample.

\section{Scanning electron microscopic study}

The morphology observed after SEM study was quite interesting. A long, somewhat elliptical, and doublestacked morphology was seen like bacilli predominantly in the photomicrograph. No oval or round shaped nanoparticles have been observed. The obtained photomicrograph was seen to be a very infrequent phenomenon. Most of the particles were in the size of 15$45 \mathrm{~nm}$. From the figure 2, it was clear that the largest morphology frequency lies at approximately 15-45 nm where this particle sizes range comprises $70 \%$ of the total AgNPs observed. The capping of the AgNPs was noted primarily at the edges of the particles than the centre, which may be due to biomolecules i.e., proteins, alkaloids, etc. 


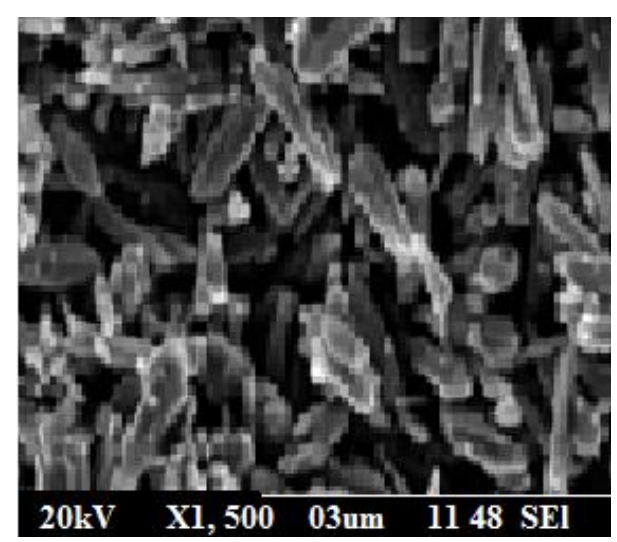

Figure 2: SEM of Lantana camara mediated synthesized AgNP sample

\section{Anti-microbial activity}

The biosynthesized AgNPs exhibited anti-microbial activity against $\mathrm{S}$. aureus where it displayed a noteworthy $\mathrm{ZOI}$ of $25.3 \pm 1.14 \mathrm{~mm}$ at MIC of $25 \mu \mathrm{g} / \mathrm{mL}$. In contrast to the standard drug ciprofloxacin, which demonstrated $33.4 \pm 1.03 \mathrm{~mm}$ ZOI at MIC of $6.25 \mu \mathrm{g} / \mathrm{mL}$, it may be concluded that the biosynthesized AgNPs have striking bactericidal potentials.

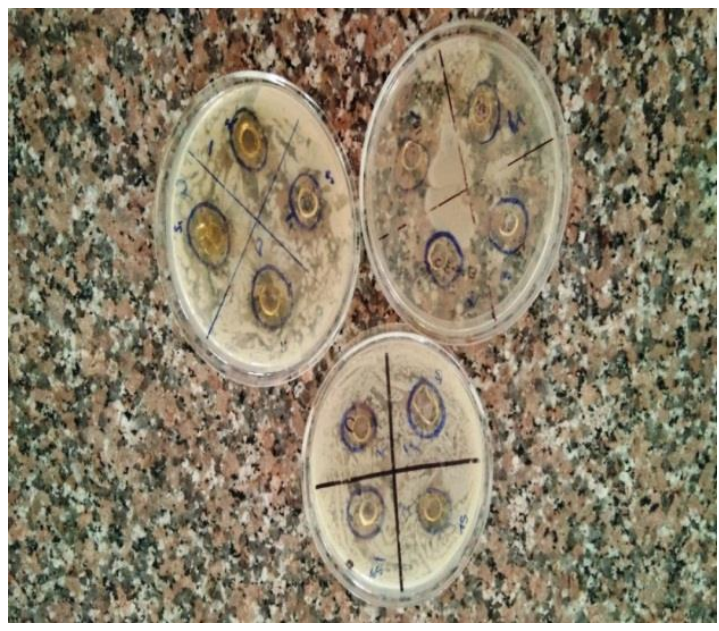

Figure 3: Zone of inhibition shown by biosynthesized AgNPs, Ciprofloxacin and Control.

\section{CONCLUSION}

The present study is a milestone in the history of silver nanomaterial synthesis via green synthesis i.e., nature inspired or using plant extract for their antibacterial potential. Lantana camara is a important member for the biosynthesis of the nanomaterials. The flower extract of Lantana camera exhibited preparation of AgNPs of range 15-45 $\mathrm{nm}$ which were bacilli-like long, somewhat elliptical, and double-stacked morphology. The UV-spectral studies also confirmed the formation of the silver nanomaterials from flower extract by optical absorption band peak at 259 $\mathrm{nm}$. The bactericidal potential screening against $S$. aureus demonstrated noteworthy activity (ZOI of $25.3 \pm 1.14 \mathrm{~mm}$ at MIC of $25 \mu \mathrm{g} / \mathrm{mL}$ ) as compared with the standard drug, ciprofloxacin. This study will certainly promote more ecofriendly less toxic synthesis of nanomaterials.

\section{REFERENCES}

1. Khalandi B, Asadi N, Milani M, Davaran S, Abadi AJ, Abasi E, Akbarzadeh A. A Review on Potential Role of Silver Nanoparticles and Possible Mechanisms of their Actions on Bacteria. Drug Research, 2017; 67 (02): 7076.

2. Marin S, Mihail Vlasceanu G, Elena Tiplea R, Raluca Bucur I, Lemnaru M, Minodora Marin M, Mihai Grumezescu A. Applications and toxicity of silver nanoparticles: a recent review. Current Topics in Medicinal Chemistry, 2015; 15(16): 1596-1604.

3. Parhi P, Mohanty C, Sahoo SK. Nanotechnology-based combinational drug delivery: an emerging approach for cancer therapy. Drug Discovery Today, 2012; 17(17-18): 1044-1052.

4. Pal S, Tak, YK, Song, JM, Does the antibacterial activity of silver nanoparticles depend on the shape of the nanoparticle? A study of the Gram negative bacterium Escherichia coli. Appl. Environ, 2007; 73: 1712-1720.

5. Parashar, UK, Saxena, SP, Srivastava, A., Bioinspired synthesis of silver nanoparticles. Dig. J. Nanomat. Biosynth, 2009; 4(1): 159-166.

6. Wijnhoven SWP, Peijnenburg WJGM, Herberts CA, Hagens WI, Oomen AG, Heugens EHW, Nano-silver: a review of available data and knowledge gaps in human and environmental risk assessment. Nanotoxicology, 2009; 3: 109-138.

7. Iravani S, Green synthesis of metal nanoparticles using plants, Green Chem, 2011; (13): 2638-2650.

8. Ghisalberti EL, Lantana camara L. (Verbenaceae). Fitoterapia 2000; 71: 467-86.

9. Dhabarde DM, Kanchanwar M, Mahapatra DK, Kamble $M A$, Ingole AR, Nature inspired fabrication and evaluation of Silver nanoparticles (AgNPs) from Terminalia catappa extract Asian Journal of Pharmacy and Pharmacology 2019; 5(3): 456-459.

Source of Support: None declared.

Conflict of Interest: None declared.

For any question relates to this article, please reach us at: editor@globalresearchonline.net

New manuscripts for publication can be submitted at: submit@globalresearchonline.net and submit_ijpsrr@rediffmail.com 